\title{
Article
}

\section{Trauma characteristics and posttraumatic growth: The mediating role of avoidance coping, intrusive thoughts and social support}

Brooks, Matthew, Graham-Kevan, Nicola, Robinson, Sarita Jane and Lowe, Michelle

Available at https://clok.uclan.ac.uk/21505/

Brooks, Matthew orcid iconORCID: 0000-0002-5469-7769, Graham-Kevan, Nicola orcid iconORCID: 0000-0003-0621-3093, Robinson, Sarita Jane orcid iconORCID: 0000-0002-4237-5412 and Lowe, Michelle (2019) Trauma characteristics and posttraumatic growth: The mediating role of avoidance coping, intrusive thoughts and social support. Psychological Trauma: Theory, Research, Practice, and Policy, 11 (2). pp. 232-238. ISSN 1942-9681

It is advisable to refer to the publisher's version if you intend to cite from the work. http://dx.doi.org/10.1037/tra0000372

For more information about UCLan's research in this area go to http://www.uclan.ac.uk/researchgroups/ and search for <name of research Group>.

For information about Research generally at UCLan please go to http://www.uclan.ac.uk/research/

All outputs in CLoK are protected by Intellectual Property Rights law, including Copyright law. Copyright, IPR and Moral Rights for the works on this site are retained by the individual authors and/or other copyright owners. Terms and conditions for use of this material are defined in the policies page. 
RUNNING HEAD: Mediators of posttraumatic growth

\title{
Trauma characteristics and posttraumatic growth: The mediating role of avoidance coping, intrusive thoughts and social support
}

\author{
Matthew T. R. Brooks, MSc*, Nicola Graham-Kevan, PhD, Sarita Robinson, PhD \\ University of Central Lancashire \\ Michelle Lowe, PhD \\ University of Bolton
}

*Corresponding Author:

Matthew Brooks

School of Psychology

University of Central Lancashire

Preston

Lancashire

PR1 2HE

United Kingdom

Email: mbrooks1@uclan.ac.uk

Phone: (+44) (0)1772 895652

Contact details for other authors:

Dr. Nicola Graham-Kevan, School of Psychology, University of Central Lancashire, Preston, PR1 2HE, UK. ngraham-kevan@uclan.ac.uk (+44) 01772893726.

Dr. Sarita Robinson, School of Psychology, University of Central Lancashire, Preston, PR1 2HE, UK. sjrobinson1@uclan.ac.uk (+44) 01772894494.

Dr. Michelle Lowe, School of Education and Psychology, University of Bolton, Deane Road, Bolton, BL3 5AB, UK. michelle.lowe@bolton.ac.uk 
Objective: Previous research suggests trauma characteristics can impact on posttraumatic growth (PTG). The current study considers whether previously identified predictors of PTG may produce different outcomes dependent on the characteristics of the trauma experienced.

Method: Active coping, avoidant coping, emotional coping, intrusive thoughts, social support and spirituality were examined as potential mediators of relationships between trauma characteristics (interpersonal trauma, number of trauma types and childhood trauma) and PTG. The responses of 268 adults exposed to multiple and wide-ranging stressors were used to generate three multiple mediation models.

Results: Intrusive thoughts and social support exerted small but significant indirect effects in all three multiple mediation models. Avoidant coping mediated associations between the number of trauma types and PTG, and the relationship between childhood trauma to PTG.

Conclusion: Relationships between trauma characteristics and PTG appear to be explained through the presence of avoidant coping strategies, intrusive thoughts and the individual's social environment, which could be the focus of intervention efforts to promote positive change.

Keywords: coping, intrusive thoughts, posttraumatic growth, social support, trauma.

Clinical impact statement: This study suggests that positive growth after trauma can be influenced by the type of traumatic event, number of trauma types experienced and childhood trauma. Avoidance coping, intrusive thoughts and social support appear to be affected by the type, frequency or timing of events, which in turn influence whether more or less growth is reported. Practitioners should be aware of the influence of trauma characteristics on coping efforts when planning interventions that support growth after adversity. 
Survivors of traumatic events can report positive, as well as negative, impacts on well-being (Linley \& Joseph, 2004), with positive changes collectively known as posttraumatic growth (PTG; Tedeschi \& Calhoun, 2004). PTG can be associated with enhanced relationships, changed views of the self, and a new life philosophy, which has been reported across a range of traumatic events, including accidents, sexual assault and chronic illnesses (Linley \& Joseph, 2004). The development of PTG and negative changes has been explained within the functional-descriptive model (FDM; Tedeschi \& Calhoun, 2004).

According to the FDM, growth occurs when attempts are made to reconcile beliefs and examine the wider meaning of the event. Negative event-related symptoms should be severe enough to challenge core beliefs and initiate cognitive processing. Within attempts to manage distressing cognitions, survivors develop an enhanced state of psychological functioning. The FDM considers PTG as an outcome of the emotional struggle following trauma. Other interpretations (e.g. Zoellner \& Maercker, 2006) also view PTG as a coping strategy employed to minimise distress. This illusory aspect reflects perceived changes in well-being, and may co-exist alongside actual PTG, as described in the FDM. While the nature of growth is debated, the study of positive changes has provided an additional perspective in which to explore adjustment post-trauma.

\section{Trauma characteristics and posttraumatic growth}

The FDM asserts that it is not the event, but the emotional struggle following trauma that is the catalyst for PTG (Tedeschi \& Calhoun, 2004). However, the FDM does not address whether specific types of trauma are more (or less) conducive to PTG. Recent research reports less growth after interpersonal events deliberately perpetrated by other persons, such rape and torture (K1lıç, Magruder, \& Koryürek, 2016), compared to non-interpersonal events such as unexpected bereavement (Shakespeare-Finch \& Armstrong, 2010). However, other 
studies have found no association between interpersonal trauma and growth (Brooks, Lowe, Graham-Kevan \& Robinson, 2016; Kira et al., 2013). It may be that the type of event could influence the emotional struggle conducive of PTG. Therefore, more research is needed to confirm the extent to which trauma type is related to growth.

In addition to trauma type, the FDM does not consider the impact of multiple types of traumatic events on PTG. Limited research suggests that individuals with multiple traumas across the lifespan are more likely to report growth (Peterson, Park, Pole, D’Andrea, \& Seligman, 2008; Shigemoto \& Poyrazli, 2013), whereas others have found similar levels of PTG regardless of the number of events experienced (Kılıç et al., 2016). Wider evidence is sparse as many PTG studies (e.g. Shakespeare-Finch \& Armstrong, 2010) focus on survivors exposed to one specific trauma type, without screening for other events people may face. The current study will therefore examine whether multiple event types contribute towards more or less growth.

The age at which traumatic events occur is also a focus of empirical study. Childhood trauma is thought to be particularly detrimental to psychological functioning, with increased distress and disrupted coping skills that regulate responses to traumatic events (Courtois, 2008; Freyd, 1996; Simons, Ducette, Kirby, Stahler, \& Shipley Jr., 2003). However, less is known about the impact of childhood trauma on PTG processes in adulthood. As childhood trauma is associated with poorer outcomes, PTG may be less likely to occur due to ineffective coping responses, although this has not yet received empirical attention.

Previous findings regarding the association between trauma characteristics and PTG which appear contradictory may be explained by mediating third factors. Psychosocial factors have been widely assessed as direct predictors of PTG, yet their influence on the relationship between trauma characteristics and growth is unknown. Understanding the psychological 
processes activated in response to different trauma characteristics would provide greater clarity as to the mechanisms whereby people report more or less PTG.

\section{Potential mediators of posttraumatic growth}

The FDM is primarily concerned with cognitive processes that drive PTG. Within the model, intrusive thoughts represent the degree to which individuals have processed the trauma (Park, 2010). Whilst associated with increased distress, intrusive thoughts are necessary to prime more deliberate attempts to understand the meaning behind the event (Tedeschi \& Calhoun, 2004). Literature (Helgeson, Reynolds, \& Tomich, 2006) finds positive associations between intrusive thoughts and PTG, with childhood, interpersonal and multiple events related to more intrusions (Graham-Kevan et al., 2015; Shakespeare-Finch \& Armstrong, 2010). In addition, intrusive thoughts can explain relationships between traumatic events and negative outcomes, such as depression (Kliewer, Lepore, Oskin, \& Johnson, 1998), although the extent to which intrusions mediate positive outcomes is unknown. Intrusive thoughts appear to influence cognitive processing post-trauma, however, the degree to which they influence PTG depending on trauma characteristics is unclear.

The FDM argues that psychosocial factors can aid traumatic event processing and PTG (Tedeschi \& Calhoun, 2004). Spiritual and active coping methods are consistently associated with increased growth (Prati \& Pietrantoni, 2009), as they can trigger a rebuilding of spiritual beliefs and reflect attempts to reduce distress. Few studies have examined the role of avoidant and emotional coping strategies on PTG. Avoidance coping is construed as maladaptive in the long-term, inhibiting recovery and sustaining PTS symptoms (Hagenaars, Fisch, \& van Minnen, 2011). However, some literature reports positive relationships between avoidance coping and PTG (London, Mercer, \& Lilly, 2017), thus providing a potential role for maladaptive or illusory coping strategies in the PTG process (Zoellner \& Maercker, 
2006). Similarly, emotional coping attempts, such as releasing supressed feelings, demonstrate mixed effects on adjustment post-trauma. Emotional strategies can entail a negative focus on emotional memories of the experience (Litman, 2006). However, research finds that emotional coping can facilitate meaning-making, encouraging PTG (Larsen \& Berenbaum, 2015). Coping may be flexible across situations, with ineffective strategies modified or discontinued in response to specific events (Kato, 2012). Thus, trauma characteristics may determine which coping strategies are used, thereby influencing the degree of PTG experienced.

Another key aspect in the FDM is social support. Findings consistently indicate that supportive relationships are associated with enhanced PTG (Prati \& Peitrantoni, 2009) as they can buffer against stress (Schumm, Briggs-Phillips, \& Hobfoll, 2006), and provide alternative perspectives that allow for meaning-making (Tedeschi \& Calhoun, 2004). Trauma characteristics could influence the extent of social support experienced, and so ultimately the level of PTG. Interpersonal traumas, such as sexual assault, may be challenging to disclose due to their deeply personal nature (Kılıç et al., 2016), with negative reactions upon disclosure associated with greater distress (Ullman \& Peter-Hagene, 2014). Therefore, event characteristics may influence psychological responses to the event, and PTG.

\section{Aims of study}

The study assessed the impact of three trauma characteristics (interpersonal trauma, number of trauma types and childhood trauma) on PTG through mediating psychosocial factors (active coping, avoidant coping, emotional coping, intrusive thoughts, social support and spirituality). The study will explore whether: i) active coping, intrusions, social support and spirituality mediate between interpersonal trauma and PTG; ii) active coping, intrusive thoughts, social support and spirituality would mediate between multiple trauma types and 
PTG; iii) active coping, intrusive thoughts, social support and spirituality would mediate between childhood trauma and PTG. It is suggested that the aforementioned factors will lead to an increase in attempts to process the trauma experienced. No hypotheses were generated for avoidant and emotional coping in three models, due to inconsistent findings.

\section{Method}

\section{Participants}

In order to attain a wide-ranging sample, participants were 268 self-selecting individuals from Northwest England who accessed the survey via university online advertisements (37.7\%), victim support services or online forums $(26.5 \%)$, and professional networking websites $(35.8 \%)$. The sample was predominantly female $(81.3 \%)$, heterosexual $(85.1 \%)$ and of White ethnicity $(83.5 \%)$, with a mean age of 33.80 years $(S D=12.31)$. Around a third of participants were either single (32.2\%) or dating/cohabiting (34.8\%). Over one third (40.4\%) of the sample were atheist, and a proportion $(16.1 \%)$ reported a disability.

Trauma history of participants is presented in Table 1 . As required by the study, all participants experienced at least one traumatic event, although the vast majority (92.2\%) reported two or more separate events. Over two-thirds (68.3\%) of the sample recorded at least one interpersonal event that was deliberately perpetrated by another person, such as physical or sexual abuse, neglect or military conflict. The average age of trauma onset was 20.36 years $(S D=11.95 ;$ range 1 to 56 years old $)$.

Insert Table 1 about here 
Traumatic experiences. Trauma history was recorded using a 12-item checklist included within the Posttraumatic Diagnostic Scale (PDS; Foa, Cashman, Jaycox, \& Perry, 1997). Participants note the frequency of their experience of events, such as natural disasters and criminal victimisation, to the best of their memory. The PDS has been validated in diverse samples exposed to a wide range of traumatic events (Foa et al., 1997). Additional items were added to account for neglect and the age the most serious event occurred. Interpersonal trauma was classed as physical assault, sexual abuse, rape, imprisonment, military conflict and neglect. Childhood trauma was considered to involve trauma under the age of 18 years, consistent with prior research (e.g. Freyd, 1996; Simons et al., 2003).

Spirituality. The Beliefs and Values Scale (BVS; King et al., 2006) is a 20-item measure of religious and spiritual beliefs. Using a five-point scale from 0 (strongly disagree) to 4 (strongly agree), participants rate the extent to which they agree with statements such as, "I believe in a personal God" and "Although I cannot always understand, I believe everything happens for a reason". The BVS has been validated in large and diverse samples (King et al., 2006), with higher scores indicative of greater religiosity or spirituality. The measure displayed excellent reliability in the study $(\alpha=.96)$.

Coping styles. The 28-item Brief COPE (Carver, 1997) assesses global coping styles on a four-item scale ranging from 0 (I haven't been doing this at all) to 3 (I have been doing this a lot). Example items include, "I've been refusing to believe it has happened" and "I've been looking for something good in what is happening", with higher scores on a particular subscale endorsing a specific coping style. The Brief COPE holds good internal reliability (Carver, 1997). The original measure includes 14 subscales consisting of only two items each, and so a principal components analysis using direct oblimin rotation was conducted to reduce the subscales. A three-factor solution emerged, which accounted for $41.3 \%$ of the variance in coping items. Factor one (active coping; $\alpha=.78$ ) included 10 items that were 
symbolic of resourceful attempts to mitigate the effects of stress, such as acceptance, planning and positive reframing. Factor two (avoidant coping; $\alpha=.77$ ) featured 10 items indicating more indirect ways of coping with stress, such as disengagement, distraction and substance use. Factor three (emotional coping; $\alpha=.82$ ) consisted of eight items endorsing strategies that may reduce the intensity of emotions, such as venting.

Posttraumatic stress. The PTSD-8 (Hansen et al., 2010) is an eight-item measure of symptoms of PTS. Participants are asked to identify their most serious traumatic event and indicate the degree to which they have experienced avoidant behaviours, hyperarousal and intrusive thoughts in relation to that event within the past two weeks. These symptoms are measured on a four-point scale of 0 (not at all) to 3 (most of the time), with items such as, "Recurrent thoughts or memories of the event" and "Feeling on guard". The PTSD-8 has been validated in numerous samples exposed to traumatic events (Hansen et al., 2010), with higher scores indicative of more severe PTS symptoms. As intrusive symptoms are most closely linked to PTG development (Tedeschi \& Calhoun, 2004), this scale was used in the current study and demonstrated good reliability $(\alpha=.86)$.

Social support. Perceived social support was assessed using the 21-item Two-Way Social Support Scale (Two-Way SSS; Shakespeare-Finch \& Obst, 2011). Example items include, "When I am feeling down there is someone I can lean on" and "I am a person others turn to for help with tasks". The Two-Way SSS demonstrates good convergent and predictive validity (Shakespeare-Finch \& Obst, 2011), with higher scores reflecting greater social support. The measure displayed excellent reliability $(\alpha=.94)$.

Posttraumatic growth. The Posttraumatic Growth Inventory-Short Form (PTGI-SF; Cann et al., 2010) is a 10-item measure of perceived positive changes after trauma, rated on a scale from 0 (no change) to 5 (very great change). Participants respond to items such as, "I 
discovered that I'm stronger than I thought I was" and "I know better that I can handle difficulties", with higher scores reflecting greater perceived change. As a brief measure, the PTGI-SF demonstrates similar reliability to the original 21-item version (Cann et al., 2010), which was replicated in this study $(\alpha=.91)$.

\section{Procedure}

Participants were invited to complete an online survey relating to their experiences and psychosocial responses to traumatic events, accessed through a weblink that provided information about the research. Participants were asked to record their symptoms within the past two weeks with reference to their most serious adverse event. The study received ethical approval from the university ethics committee.

\section{Data analysis}

First, Pearson's correlations examined the magnitude and direction of associations between key study variables. Next, mediation analyses were conducted to determine direct and indirect effects with 5000 bootstrapped samples and bias-corrected $95 \%$ confidence intervals (BCa CI) using the SPSS PROCESS macro (Hayes, 2013). This approach is more powerful than casual steps analysis as it does not require all paths to be significant.

Confidence intervals that do not contain zero indicate a significant indirect effect. Unstandardised regression coefficients, direct and indirect effects are reported in line with current recommendations (Hayes, 2013), although completely standardised indirect effect sizes $\left(a b_{c s}\right)$ are also provided in this study to allow for consideration of effect sizes. Effect sizes are identified as small ( $a b_{c s}$ of .01 to .08), medium ( $a b_{c s}$ of .09 to .24 ) or large ( $a b_{c s} \geq$ .25 ; Hayes, 2013).

To address the three hypotheses, three separation mediation analyses were conducted with interpersonal trauma, number of trauma types and childhood trauma as independent 
variables. Spirituality, active coping, avoidant coping, emotional coping, intrusions, and social support were entered as mediators (see Figure 1, Supplementary materials, for visualisation). To minimise type I errors given the number of variables in the bivariate correlational analysis, a more conservative alpha level of $p<.01$ was used. However, an alpha level of $p<.05$ was retained for both direct and indirect effects in the mediation analysis as it has paths equivalent to partial correlations. In addition, while the specification of the models was theoretically driven, recommendations for cross-sectional mediation analyses (Preacher \& Hayes, 2004) suggest that reverse models are tested to provide support for the directionality of relationships (see Supplementary Materials for results).

\section{Results}

Correlational analysis

Insert Table 2 about here

Means, standard deviations and correlations for the key study variables are presented in Table 2. Correlational analyses indicated that event characteristics were more closely related to intrusive thoughts, rather than PTG. PTG was found to be unrelated to avoidant coping and positively associated with all other psychosocial factors $(p<.01)$.

\section{Mediation analysis}

Insert Table 3 about here

The results of the mediation analyses are presented in Table 3. In respect of the first hypothesis, the mediation model with interpersonal trauma and psychosocial mediators 
explained $40 \%$ of the variance in PTG scores $[F(7,260)=25.04, p<.05]$. Significant direct effects $(p<.05)$ between interpersonal trauma and PTG were observed for intrusive thoughts and social support only. For indirect effects, intrusions demonstrated significant positive $\left(a b_{c s}\right.$ $=.07$; BCa CI: $.03, .12)$ and social support significant negative $\left(a b_{c s}=-.02\right.$; BCa CI: -.05, .03) indirect effects on the relationship with PTG when controlling for all other psychosocial variables.

The second mediation model with number of trauma types revealed few direct effects $[F(7,260)=24.70, p<.05]$. Significant direct effects $(p<.05)$ between number of trauma types and PTG were found for avoidance coping, intrusive thoughts and social support. The model explained $40 \%$ of the variance in PTG scores and revealed that avoidant coping $\left(a b_{c s}=\right.$ -.04 ; BCa CI: -.09, -.02) and social support $\left(a b_{c s}=-.02\right.$; BCa CI: -.05, -.01) exerted significant negative indirect effects on the relationship between number of trauma types and PTG. Intrusive thoughts significantly and positively mediated $\left(a b_{c s}=.08 ; \mathrm{BCa}\right.$ CI: .04, .13) the same relationship.

Finally, the third model with childhood trauma as the independent variable explained $41 \%$ of the variance in PTG scores $[F(7,260)=25.35, p<.05]$. Significant direct effects $(p$ $<.05)$ were observed for avoidance coping, intrusive thoughts and social support on PTG. In terms of mediation, avoidant coping $\left(a b_{c s}=-.04\right.$; BCa CI: -.09, -.02) and social support $\left(a b_{c s}\right.$ $=-.02 ; \mathrm{BCa}$ CI: $-.05,-.01)$ displayed significant negative indirect effects on the association between childhood trauma and PTG, while intrusions demonstrated a positive indirect effect $\left(a b_{c s}=.04 ; \mathrm{BCa}\right.$ CI: .01, .08).

\section{Discussion}

The current study aimed to extend the FDM (Tedeschi \& Calhoun, 2004), by explicitly examining how psychosocial factors result in positive change as a function of the 
type, frequency or onset of trauma experienced. While psychosocial factors have been traditionally explored as direct predictors of growth, the current study went further to determine indirect relationships between trauma characteristics and PTG. Traumatic events themselves do not result in growth, and so three hypotheses were presented that anticipated that active coping, intrusive thoughts, social support and spirituality would separately explain relationships between the type, frequency and timing of trauma, and PTG. Subjective interpretations of traumatic events are thought to be key to psychological adjustment (Linley \& Joseph, 2004), and so it is important to identify the mechanisms that indirectly link trauma characteristics to positive change.

Results of the current study offered support for the hypotheses regarding the relationship between trauma characteristics, psychosocial factors and PTG. Intrusive thoughts mediated the relationship between interpersonal trauma and PTG. Although interpersonal acts are generally associated with increased PTS symptoms compared to non-interpersonal traumas (Courtois, 2008), our results suggest intrusive thoughts may have adaptive value. Within the FDM, intrusive thinking is conceived as a natural response to stressful experiences that are seismic enough to challenge world views (Tedeschi \& Calhoun, 2004). These automatic thoughts can precipitate intentional attempts to reassess the event, which can lead to PTG. Social support also exerted indirect effects on PTG. Interpersonal trauma may be particularly difficult to disclose to others, especially if perpetrated by those in the person's immediate social environment (Kılıç et al., 2016). Yet the presence of social networks could buffer against stress (Schumm et al., 2006) or provide opportunities to adopt new perspectives associated with increased growth (Tedeschi \& Calhoun, 2004). Intrusions and social support therefore appear to mediate the levels of PTG following interpersonal trauma.

The study identified factors that mediate PTG following multiple trauma types. Intrusive thoughts explained the relationship between multiple trauma types and PTG, again 
underlining the importance of intrusions within the PTG process as indicated in the FDM (Tedeschi \& Calhoun, 2004). The relationship between multiple trauma types and PTG was also explained by avoidance coping. Avoidance coping may be adaptive in circumstances where the person may lack control over their ability to manage multiple types of events (Kato, 2012). However, there was no evidence to support that PTG in this sample could reflect illusory growth, as less avoidance was associated with more growth in the mediation model (Zoellner \& Maercker, 2006). Furthermore, and as hypothesised, the indirect pathway through social support was significant. Multiple trauma types can adversely impact on interpersonal relationships through decreased trust and increased withdrawal from social situations (Courtois, 2008). However, social support could promote more effective coping strategies that encourage growth following multiple events (Prati \& Pietrantoni, 2009). Overall, multiple trauma types could encourage coping strategies conducive to PTG.

Finally, the study also provided insight into potential mediators of PTG following childhood trauma. Consistent with the other models, intrusive thoughts mediated relationships with growth. The detrimental effect of childhood adversity on PTS symptoms is well-known (Courtois, 2008), however, the findings suggest that intrusive thoughts are equally crucial following childhood trauma to promote PTG. The FDM asserts that intrusions signify cognitive processing indicative of the growth process (Tedeschi \& Calhoun, 2004). Consistent with other research (London et al., 2017), childhood trauma was unrelated to PTG, although had an indirect effect via avoidance coping. Evidence indicates greater use of avoidance coping in childhood trauma survivors (Simons et al., 2003), which may arise out of a need to maintain relationships with abusive caregivers for survival purposes (Freyd, 1996). While an adaptive strategy to reduce distress, the results suggest a reduction in avoidance coping can enhance PTG following childhood trauma. This finding may imply a more constructive aspect of growth that is associated with less reliance on maladaptive strategies 
that perpetuate distress in the long-term (Zoellner \& Maercker, 2006). Social support also exerted indirect effects on the relationship between childhood trauma and PTG. Childhood trauma may create difficulties forming social relationships that are necessary to develop additional perspectives needed for PTG (Courtois, 2008; Tedeschi \& Calhoun, 2004). Intrusive thoughts, avoidant coping and social support can therefore promote PTG in childhood trauma survivors.

Contrary to expectations, and some recent literature (London et al., 2017), the indirect pathways for active coping and spirituality were not significant in any model. This is surprising as both constructs have been shown to strongly and positively influence PTG (Prati \& Pietrantoni, 2009). The adaptiveness of coping methods may be dependent on the context in which they occur (Kato, 2012), such that active coping and spirituality could lead to more distress in protracted trauma situations where there are few opportunities to effect change. Furthermore, emotional coping did not mediate PTG in any model. Emotional coping is intertwined with revisiting distressing memories (Litman, 2006), and may not be seen as adaptive compared to avoidant strategies that minimise distress (Kato, 2012). Research on emotional regulation strategies and PTG is very limited (Larsen \& Berenbaum, 2015) and so future studies should address whether these rival mechanisms exist. Therefore, active coping, emotional coping and spirituality do not appear to influence PTG depending on trauma characteristics.

The study highlighted how specific psychosocial factors are more or less conducive to PTG dependent upon the characteristics of the traumatic events experienced. Interventions may be more responsive if clinicians are mindful of the trauma backgrounds within their clients, which provide a better indication of PTG rather than focusing on growth from a single event (Kira et al., 2013). Avoidance coping, intrusive thoughts and social support were affected by trauma characteristics and subsequently influenced PTG. As psychosocial factors 
may be context-dependent (Kato, 2012), it may be that trauma-specific efforts to reduce a reliance on avoidance coping, guide more effortful intrusive thought processes and identify positive social support networks could benefit PTG in those with interpersonal, multiple and childhood trauma.

The study is not without limitations. The cross-sectional nature of this study means that causality between factors responsible for PTG cannot be strongly established, although reverse models were tested to enhance confidence in the directionality of the findings. However, longitudinal investigations should assess whether similar findings are observed across time. While the models accounted for up to $41 \%$ of the variance in PTG scores, they demonstrated small effect sizes. This finding implies that other factors may mediate growth, such as the perceived severity of the trauma and type of rumination (Brooks, Graham-Kevan, Lowe, \& Robinson, 2017; García, Cova, Rincón, \& Vázquez, 2015) which should be a focus in future studies. Additionally, the results do not speak as to whether actual growth has occurred (Zoellner \& Maercker, 2006), and only reflect perceived PTG.

The current study was the first to identify how trauma characteristics impact on specific psychosocial factors that may explain why some people report more or less PTG. Intrusive thoughts and social support were found to be robust mediators that explain this relationship compared to avoidance coping, which was less consistent across characteristics. Therefore, it is important to understand the impact of trauma characteristics on psychological functioning to tailor appropriate support to encourage PTG. 


\section{References}

Brooks, M., Graham-Kevan, N., Lowe, M., \& Robinson, S. (2017). Rumination, event centrality, and perceived control as predictors of post-traumatic growth and distress: The Cognitive Growth and Stress model. British Journal of Clinical Psychology, 56, 286-302. doi: 10.1111/bjc.12138

Brooks, M., Lowe, M., Graham-Kevan, N., \& Robinson, S. (2016). Posttraumatic growth in students, crime survivors and trauma workers exposed to adversity. Personality and Individual Differences, 98, 199-207. doi: 10.1016/j.paid.2016.04.051

Cann, A., Calhoun, L.G., Tedeschi, R. G., Taku, K., Vishnevsky, T., Triplett, K.N., \& Danhauer, S.C. (2010). A short form of the Posttraumatic Growth Inventory. Anxiety, Stress \& Coping, 23, 127-137. doi: 10.1080/10615800903094273

Carver, C.S. (1997). You want to measure coping but your protocol's too long: Consider the Brief COPE. International Journal of Behavioural Medicine, 4, 92-100. doi: 10.1207/s15327558ijbm0401_6

Courtois, C. A. (2008). Complex trauma, complex reactions: Assessment and treatment. Psychological Trauma: Theory, Research, Practice, and Policy, S, 86-100. doi: 10.1037/1942-9681.S.1.86

Foa, E.B., Cashman, L., Jaycox, L., \& Perry, K. (1997). The validation of a self-report measure of posttraumatic stress disorder: The Posttraumatic Diagnostic Scale. Psychological Assessment, 9, 445-451. doi: 10.1037/1040-3590.9.4.445

Freyd, J. J. (1996). Betrayal trauma: The logic of forgetting childhood abuse. Cambridge, MA: Harvard University Press. 
García, F. E., Cova, F., Rincón, P., \& Vázquez, C. (2015). Trauma or growth after a natural disaster? The mediating role of rumination processes. European Journal of Psychotraumatology, 6, 26557. doi: 10.3402/ejpt.v6.26557

Graham-Kevan, N., Brooks, M., Willan, V. J., Lowe, M., Robinson, P., Khan, R., ... \& Bryce, J. (2015). Repeat victimisation, retraumatisation and victim vulnerability. The Open Criminology Journal, 8, 36-48. doi: 10.2174/1874917801508010036

Joseph, S., \& Linley, P. A. (2006). Growth following adversity: Theoretical perspectives and implications for clinical practice. Clinical Psychology Review, 26(8), 1041-1053. doi: 10.1016/j.cpr.2005.12.006

Hansen, M., Anderson, T.E., Armour, C., Elklit, A. Palic, S., \& Mackrill, T. (2010). PTSD-8: A short PTSD inventory. Clinical Practice \& Epidemiology in Mental Health, 6, 101108. doi: $10.2174 / 1745017901006010101$

Hayes, A.F. (2013). Introduction to mediation, moderation, and conditional process analysis: A regression-based approach. New York: Guilford Press.

Hagenaars, M. A., Fisch, I., \& van Minnen, A. (2011). The effect of trauma onset and frequency on PTSD-associated symptoms. Journal of Affective Disorders, 132, 192199. doi: $10.1016 /$ j.jad.2011.02.017

Helgeson, V. S., Reynolds, K. A., \& Tomich, P. L. (2006). A meta-analytic review of benefit finding and growth. Journal of Consulting and Clinical Psychology, 74, 797-816. doi: 10.1037/0022-006X.74.5.797

Kato, T. (2012). Development of the Coping Flexibility Scale: Evidence for the coping flexibility hypothesis. Journal of Counseling Psychology, 59, 262-273. doi: $10.1037 / \mathrm{a} 0027770$ 
Kılıç, C., Magruder, K. M., \& Koryürek, M. M. (2016). Does trauma type relate to posttraumatic growth after war? A pilot study of young Iraqi war survivors living in Turkey. Transcultural Psychiatry, 53, 110-123. doi: 10.1177/1363461515612963

King, M., Jones, L., Barnes, K., Low, J., Walker, C., Wilkinson, J., Mason, C., Sutherland, J., \& Tookman, A. (2006). Measuring spiritual belief: Development and standardisation of a Beliefs and Values Scale. Psychological Medicine, 36, 417-425. doi: $10.1017 / \mathrm{S} 003329170500629 \mathrm{X}$

Kira, I. A., Aboumediene, S., Ashby, J. S., Odenat, L., Mohanesh, J., \& Alamia, H. (2013). The dynamics of posttraumatic growth across different trauma types in a Palestinian sample. Journal of Loss and Trauma, 18, 120-139. doi:

$10.1080 / 15325024.2012 .679129$

Kliewer, W., Lepore, S. J., Oskin, D., \& Johnson, P. D. (1998). The role of social and cognitive processes in children's adjustment to community violence. Journal of Consulting and Clinical Psychology, 66, 199-209. doi: 10.1037/0022-006X.66.1.199

Larsen, S.E., \& Berenbaum, H. (2015). Are specific emotion regulation strategies differentially associated with posttraumatic growth versus stress? Journal of Aggression, Maltreatment \& Trauma, 24(7), 794-808. doi:

$10.1080 / 10926771.2015 .1062451$

Linley, P.A., \& Joseph, S. (2004). Positive change following trauma and adversity: A review. Journal of Traumatic Stress, 17, 11-21. doi: 10.1023/B:JOTS.0000014671.27856.7e

Litman, J. A. (2006). The COPE inventory: Dimensionality and relationships with approachand avoidance-motives and positive and negative traits. Personality and Individual Differences, 41, 273-284. doi: 10.1016/j.paid.2005.11.032 
London, M. J., Mercer, M. C., \& Lilly, M. M. (2017). Considering the impact of early trauma on coping and pathology to predict posttraumatic growth among 9-1-1 telecommunicators. Journal of Interpersonal Violence. Advance online publication. doi: $10.1177 / 0886260517716942$

Park, C. L. (2010). Making sense of the meaning literature: an integrative review of meaning making and its effects on adjustment to stressful life events. Psychological Bulletin, 136, 257-301. doi: 10.1037/a0018301

Peterson, C., Park, N., Pole, N., D'Andrea, W., \& Seligman, M.E. (2008). Strengths of character and posttraumatic growth. Journal of Traumatic Stress, 21, 214-217. doi: $10.1002 / \mathrm{jt}$

Prati, G., \& Pietrantoni, L. (2009). Optimism, social support, and coping strategies as factors contributing to posttraumatic growth: A meta-analysis. Journal of Loss and Trauma, 14, 364-388. doi: 10.1080/15325020902724271

Preacher, K. J., \& Hayes, A. F. (2004). SPSS and SAS procedures for estimating indirect effects in simple mediation models. Behavior Research Methods, 36, 717-731. doi: 10.3758/BF03206553

Schumm, J. A., Briggs-Phillips, M., \& Hobfoll, S. E. (2006). Cumulative interpersonal traumas and social support as risk and resiliency factors in predicting PTSD and depression among inner-city women. Journal of Traumatic Stress, 19, 825-836. doi: 10.1002/jts.20159

Shakespeare-Finch, J., \& Armstrong, D. (2010). Trauma type and posttrauma outcomes: Differences between survivors of motor vehicle accidents, sexual assault, and bereavement. Journal of Loss and Trauma, 15, 69-82. doi: $10.1080 / 15325020903373151$ 
Shakespeare-Finch, J., \& Obst, P.L. (2011). The development of the 2-way social support scale: A measure of giving and receiving emotional and instrumental support. Journal of Personality Assessment, 93, 483-490. doi: 10.1080/00223891.2011.594124

Shigemoto, Y., \& Poyrazli, S. (2013). Factors related to posttraumatic growth in U.S. and Japanese college students. Psychological Trauma: Theory, Research, Practice, and Policy, 5, 128-134. doi: 10.1037/a0026647

Simons, L., Ducette, J., Kirby, K. C., Stahler, G., \& Shipley Jr, T. E. (2003). Childhood trauma, avoidance coping, and alcohol and other drug use among women in residential and outpatient treatment programs. Alcoholism Treatment Quarterly, 21, 37-54. doi: 10.1300/J020v21n04_04

Tedeschi, R.G., \& Calhoun, L.G. (2004). Posttraumatic growth: Conceptual foundations and empirical evidence. Psychological Inquiry, 15, 1-18. doi: 10.1207/s15327965pli1501_01

Ullman, S. E., \& Peter-Hagene, L. (2014). Social reactions to sexual assault disclosure, coping, perceived control, and PTSD symptoms in sexual assault victims. Journal of Community Psychology, 42, 495-508. doi: 10.1002/jcop.21624

Zoellner, T., \& Maercker, A. (2006). Posttraumatic growth in clinical psychology-A critical review and introduction of a two component model. Clinical Psychology Review, 26, 626-653. doi: 10.1016/j.cpr.2006.01.008 
Table 1.

Frequency of trauma exposure in the sample.

\begin{tabular}{lcc}
\hline Trauma type & $N$ & $\%$ \\
\hline Accident & 130 & 48.5 \\
Natural disaster & 26 & 9.7 \\
Serious attack/threat by partner & 80 & 29.9 \\
Serious attack/threat by other & 102 & 38.1 \\
Child sexual abuse & 93 & 34.7 \\
Rape by partner & 36 & 13.4 \\
Rape by other & 55 & 20.5 \\
Imprisonment & 24 & 9.0 \\
Military conflict & 15 & 5.6 \\
Serious or terminal illness & 72 & 26.9 \\
Bereavement & 140 & 52.2 \\
Neglect & 86 & 32.1 \\
Other event & 50 & 18.7 \\
\hline
\end{tabular}


Table 2.

Descriptive statistics and intercorrelations between key study variables.

\begin{tabular}{|c|c|c|c|c|c|c|c|c|c|c|c|c|c|}
\hline & $M$ & $S D$ & Range & 1 & 2 & 3 & 4 & 5 & 6 & 7 & 8 & 9 & 10 \\
\hline 1. Interpersonal trauma ${ }^{a}$ & - & - & - & - & $.45^{*}$ & $.18^{*}$ & .08 & .08 & .06 & $.25^{*}$ & -.14 & .07 & .02 \\
\hline 2. Number of trauma types & 4.03 & 2.48 & $1-13$ & & - & .13 & .10 & $.22 *$ & .01 & $.31 *$ & -.15 & .12 & .07 \\
\hline 3. Childhood trauma ${ }^{a}$ & - & - & - & & & - & -.08 & $.21^{*}$ & -.04 & .15 & -.13 & -.11 & -.16 \\
\hline 4. Active coping & 16.14 & 5.80 & $0-26$ & & & & - & .08 & $.46^{*}$ & .12 & $.22 *$ & .12 & $.42 *$ \\
\hline 5. Avoidant coping & 9.28 & 5.59 & $0-30$ & & & & & - & $.19^{*}$ & $.50 *$ & $-.43 *$ & -.05 & -.09 \\
\hline 6. Emotional coping & 10.28 & 5.51 & $0-24$ & & & & & & - & $.19 *$ & $.25^{*}$ & $.43^{*}$ & $.43^{*}$ \\
\hline 7. Intrusive thoughts & 6.14 & 3.26 & $0-12$ & & & & & & & - & $-.22 *$ & .13 & $.22 *$ \\
\hline 8. Social support & 76.93 & 19.50 & $16-105$ & & & & & & & & - & $.19 *$ & $.30 *$ \\
\hline 9. Spirituality & 37.89 & 21.26 & $0-79$ & & & & & & & & & - & $.42^{*}$ \\
\hline 10. Posttraumatic growth & 25.23 & 13.09 & $0-50$ & & & & & & & & & & - \\
\hline
\end{tabular}

Note. ${ }^{\text {a }}$ Interpersonal trauma was dummy coded: $0=$ no interpersonal trauma; 1 = interpersonal trauma. Childhood trauma was dummy coded: 0 $=$ no childhood trauma; 1 = childhood trauma. $* p<.01$. 
Table 3.

Results of multiple mediation analyses examining direct and indirect effects of trauma characteristics on posttraumatic growth through psychosocial factors.

\begin{tabular}{|c|c|c|c|c|c|c|c|c|}
\hline \multirow[b]{2}{*}{$\begin{array}{l}\text { Independent } \\
\text { variable }(X)\end{array}$} & \multirow[b]{2}{*}{ Mediator $(M)$} & \multicolumn{4}{|c|}{ Direct effect $\left(c^{\prime}\right)$} & \multicolumn{2}{|c|}{ Indirect effect $(a b)$} & \multirow[b]{2}{*}{$\begin{array}{c}\text { Upper } 95 \% \\
\text { ВCa }\end{array}$} \\
\hline & & $b$ & $S E$ & $p$ & $b$ & Boot $S E$ & $\begin{array}{c}\text { Lower } 95 \% \\
\text { BCa }\end{array}$ & \\
\hline \multirow{7}{*}{$\begin{array}{c}\text { Interpersonal } \\
\text { trauma }\end{array}$} & & \multicolumn{7}{|c|}{ Posttraumatic growth $(Y)$} \\
\hline & Active coping & 1.04 & .76 & .171 & .67 & .52 & -.26 & 1.82 \\
\hline & Avoidant coping & .95 & .73 & .194 & -.48 & .38 & -1.42 & .15 \\
\hline & Emotional coping & .70 & .72 & .332 & .26 & .30 & -.16 & 1.05 \\
\hline & Intrusive thoughts & 1.71 & .41 & $<.001$ & 1.85 & .58 & .89 & 3.16 \\
\hline & Social support & -5.84 & 2.54 & .022 & -.44 & .30 & -1.30 & -.04 \\
\hline & \multirow{2}{*}{ Spirituality } & 3.29 & 2.79 & .239 & .52 & .46 & -.28 & 1.61 \\
\hline \multirow{7}{*}{$\begin{array}{l}\text { Number of } \\
\text { trauma types }\end{array}$} & & \multicolumn{7}{|c|}{ Posttraumatic growth $(Y)$} \\
\hline & \multirow{2}{*}{$\begin{array}{c}\text { Active coping } \\
\text { Avoidant coping }\end{array}$} & .23 & .14 & .107 & .15 & .11 & -.04 & .40 \\
\hline & & .48 & .14 & $<.001$ & -.23 & .10 & -.46 & -.09 \\
\hline & Emotional coping & .02 & .13 & .873 & .01 & .06 & -.10 & .14 \\
\hline & Intrusive thoughts & .41 & .08 & $<.001$ & .42 & .13 & .21 & .71 \\
\hline & Social support & -1.18 & .48 & .013 & -.10 & .06 & -.26 & -.02 \\
\hline & Spirituality & 1.01 & .52 & .054 & .16 & .10 & -.01 & .39 \\
\hline
\end{tabular}


Table 3 (continued).

\begin{tabular}{|c|c|c|c|c|c|c|c|c|}
\hline \multirow[b]{2}{*}{$\begin{array}{l}\text { Independent } \\
\text { variable }(X)\end{array}$} & \multirow[b]{2}{*}{ Mediator $(M)$} & \multicolumn{4}{|c|}{ Direct effect $\left(c^{\prime}\right)$} & \multicolumn{2}{|c|}{ Indirect effect $(a b)$} & \multirow[b]{2}{*}{$\begin{array}{c}\text { Upper 95\% } \\
\text { ВCa }\end{array}$} \\
\hline & & $b$ & $S E$ & $p$ & $b$ & Boot $S E$ & $\begin{array}{c}\text { Lower } 95 \% \\
\mathrm{BCa}\end{array}$ & \\
\hline \multirow{7}{*}{$\begin{array}{c}\text { Childhood } \\
\text { trauma }\end{array}$} & & \multicolumn{7}{|c|}{ Posttraumatic growth $(Y)$} \\
\hline & Active coping & -.96 & .72 & .179 & -.59 & .49 & -1.69 & .24 \\
\hline & Avoidant coping & 2.37 & .68 & .001 & -1.06 & .45 & -2.21 & -.38 \\
\hline & Emotional coping & -.43 & .68 & .531 & -.16 & .28 & -.84 & .31 \\
\hline & Intrusive thoughts & .99 & .40 & .009 & 1.03 & .47 & .28 & 2.14 \\
\hline & Social support & -5.26 & 2.39 & .028 & -.44 & .29 & -1.24 & -.04 \\
\hline & Spirituality & -4.69 & 2.61 & .073 & -.70 & .44 & -1.74 & .00 \\
\hline
\end{tabular}

Notes. $S E=$ standard error; $95 \% \mathrm{BCa}=95 \%$ bias-corrected confidence interval; Boldface values indicate significant effects $(p<.05) ; c^{\prime}=$

unstandardised direct effects of the independent variable on the dependent variable $(X \rightarrow Y)$ controlling for the mediator; $a b=$ unstandardised indirect effects of the independent variable on the dependent variable via the mediator $(X \rightarrow M \rightarrow Y)$. 


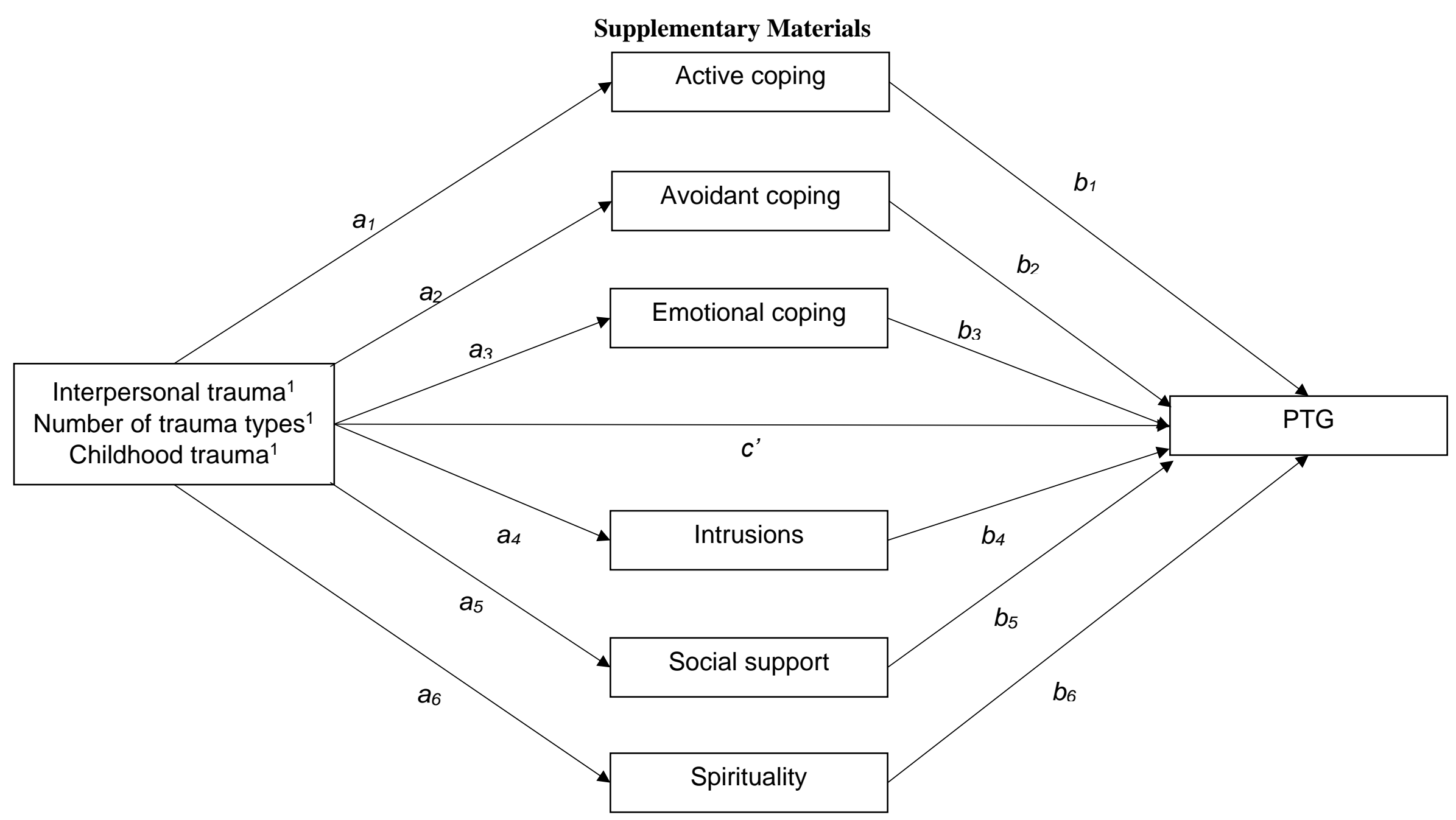

Figure 1. Multiple mediator model depicting psychosocial factors as mediators of the relationship between trauma characteristics and PTG. ${ }^{1}$

These characteristics were entered as independent variables in three separate multiple mediation models. 


\section{Reverse mediation models}

While the specification of the models was based on prior theory and literature, recommendations for cross sectional mediation analyses (Preacher \& Hayes, 2004) suggest that reverse models are tested to increase confidence in the hypothesised direction of relationships within the mediation model. Within these models, trauma characteristics preceded PTG as the latter arises from the emotional struggle with trauma (Tedeschi \& Calhoun, 2004); however, the mediator and outcome (PTG) were substituted to allow for plausible bidirectional associations. For example, while intrusions, social support and spirituality may mediate associations between trauma characteristics and growth, literature also indicates that increased distress, enhanced relationships and greater spirituality are also a product of PTG (Tedeschi \& Calhoun, 2004).

\section{Results}

None of the reverse mediation analyses for the interpersonal trauma and number of trauma types indicated significant indirect effects. However, bidirectional associations were revealed in the childhood trauma mediation model. Reverse models with PTG as the mediator indicated positive associations with active coping $\left(b=.19, t=7.43, p<.01 ; a b=-.76 ; a b_{c s}=\right.$ -.07 ; BCa CI: -.12, -.02), emotional coping $\left(b=.18, t=7.74, p<.01 ; a b=-.75 ; a b_{c s}=-.07\right.$; BCa CI: $-.13,-.02)$, intrusions $\left(b=.06, t=4.10, p<.01 ; a b=-.25 ; a b_{c s}=-.04 ;\right.$ BCa CI: -.10 , -.08), social support $\left(b=.43, t=4.91, p<.01 ; a b=-1.77 ; a b_{c s}=-.05\right.$; BCa CI: -.71, -.09) and spirituality $\left(b=.67, t=7.25, p<.01 ; a b=-.2 .72 ; a b_{c s}=-.06 ; \mathrm{BCa}\right.$ CI: $\left.-.12,-.02\right)$, each demonstrating small indirect effects.

\section{Discussion}


For the childhood trauma reverse mediation models, PTG exerted significant indirect effects on active coping, emotional coping, intrusive thoughts, social support and spirituality. The findings are broadly in line with the functional-descriptive model (Tedeschi \& Calhoun, 2004) and the wider PTG literature (e.g. Linley \& Joseph, 2004), that indicate that growth is associated with enhanced well-being. Although unmeasured in this study, it is possible that those who report PTG can become more optimistic after overcoming prior traumas, which can lead individuals to adopt and rely on active coping strategies (Prati \& Pietrantoni, 2009). 'Successful' coping attempts may therefore embolden individuals to deal with future events. Additionally, while studies of emotional strategies and PTG are limited (Larsen \& Berenbaum, 2015), the positive association between emotional coping and social support may mean that emotional coping is a proxy for increased social support and expression following PTG. Therefore, active coping, avoidant coping and emotional coping are possible outcomes that may be reported as a result of growth.

Intrusive thoughts, social support and spirituality were found to mediate the indirect relationship between childhood trauma and PTG. The finding that intrusive thoughts exerted indirect effects is supported by existing models (e.g. Tedeschi \& Calhoun, 2004) which construe intrusive thoughts as a driver of growth processes, and as a product of attempts to understand the trauma which can be distressing. A bidirectional mediation relationship was found between social support and PTG. Childhood trauma may create difficulty in forming social relationships that are necessary to develop additional perspectives needed for PTG (Courtois, 2008; Tedeschi \& Calhoun, 2004), yet enhanced social support may also be a consequence of growth, thus confirming associations that were previously unclear in the literature (Linley \& Joseph, 2004; Prati \& Pietrantoni, 2009). Furthermore, available evidence suggests that spiritual beliefs can be enhanced or diminished following trauma (Walker et al., 2009), although the mechanisms by which this occurs are presently unclear. 
Spiritual coping appears to be influenced by the onset of trauma and PTG, which may allow survivors to find hope and meaning in their experiences (Tedeschi \& Calhoun, 2004; Walker et al., 2009). Therefore, PTG following childhood trauma can entail more distress, but also more social support and spiritual coping in an attempt to find meaning. 